Bentham OPEN
CrossMark

\title{
Lithium-Induced Downbeat Nystagmus and Horizontal Gaze Palsy
}

\author{
Jesper Skovlund Jørgensen ${ }^{1, *}$, Lisbeth Landschoff Lassen ${ }^{2}$ and Marianne Wegener ${ }^{1}$ \\ ${ }^{I}$ Department of Ophthalmology, Rigshospitalet-Glostrup, Copenhagen, Denmark \\ ${ }^{2}$ Department of Neurology, Neuroscience Center, Rigshospitalet-Glostrup, Copenhagen, Denmark
}

Abstract: We report a case of lithium-induced downbeat nystagmus and horizontal gaze palsy in a 62-year-old woman who was treated for a bipolar affective disorder with lithium carbonate for one month. At presentation serum lithium was within therapeutic range. No alternative causes of the ocular motility disturbances were found, and the patient improved significantly as lithium carbonate was discontinued.

Keywords: Adverse effects, Downbeat nystagmus, Gaze palsy, Lithium.

\section{INTRODUCTION}

Downbeat nystagmus (DBN) is a well-known neurotoxic side effect of lithium treatment [1]. We report a rare case of lithium-induced DBN combined with horizontal gaze palsy. To our knowledge, this observation was only reported once previously [2].

Lithium salts are commonly prescribed for bipolar affective disorders and depression. The therapeutic range is narrow and neurological side effects are well described, and might occur despite serum-lithium levels within the therapeutic range $[1,3]$.

\section{Case Report}

A 62-year-old woman was admitted at the Department of Neurology, Rigshospitalet-Glostrup, with generalized weakness, extremity tremor and recurrent falls. Past medical history included epilepsy and depressions treated with lamotrigine $75 \mathrm{mg}$ /day, valproate $1500 \mathrm{mg}$ /day and venlafaxin $375 \mathrm{mg} /$ day. Four weeks before presentation lithium carbonate $600 \mathrm{mg} /$ day was added. The patient had no history of alcohol abuse.

Neurological examination revealed a normal mental status, gross extremity tremor, unsteady gait and saccadic eye movements. Serum lithium level was $0.78 \mathrm{mmol} / \mathrm{L}(0.5-0.8 \mathrm{mmol} / \mathrm{L})$, serum magnesium level was $0.87 \mathrm{mmol} / \mathrm{L}$ (0.71 - $0.94 \mathrm{mmol} / \mathrm{L})$, and serum vitamin B12 level was $688 \mathrm{pmol} / \mathrm{L}$ (> $200 \mathrm{pmol} / \mathrm{L})$. Magnetic resonance imaging of the brain, cerebrospinal fluid analysis as well as electroencephalography were normal. Paraneoplastic autoantibodies in serum were negative for Anti-amphiphysin, anti-CV2, anti-PMNA2, anti-Ri, anti-Yo, anti-ANNA1. In the following 3 weeks of hospitalization the patient deteriorated with progressive ataxia, tremor, cognitive impairment, and complaints of diplopia. Neuro-ophthalmic examination revealed upward gaze deviation, DBN and horizontal gaze palsy (Fig. 1). The patient was only shortly able to bring her eyes in the primary position of gaze, which elicited DBN, and was unable to bring her eyes below the horizontal plane. No voluntary horizontal saccades or pursuit movements could be elicited, and the gaze palsies were not overcome by activation of the vestibulo-ocular reflexes by doll's head manoeuvre. Pupils were equal and light reflexes normal. The patient was unable to cooperate to formal visual acuity assessment.

\footnotetext{
* Address correspondence to this author at the Department of Ophthalmology Rigshospitalet-Glostrup Nordre Ringvej 572600 Glostrup; Denmark; Tel: +455133788; E-mail: jskovlund@hotmail.com
} 


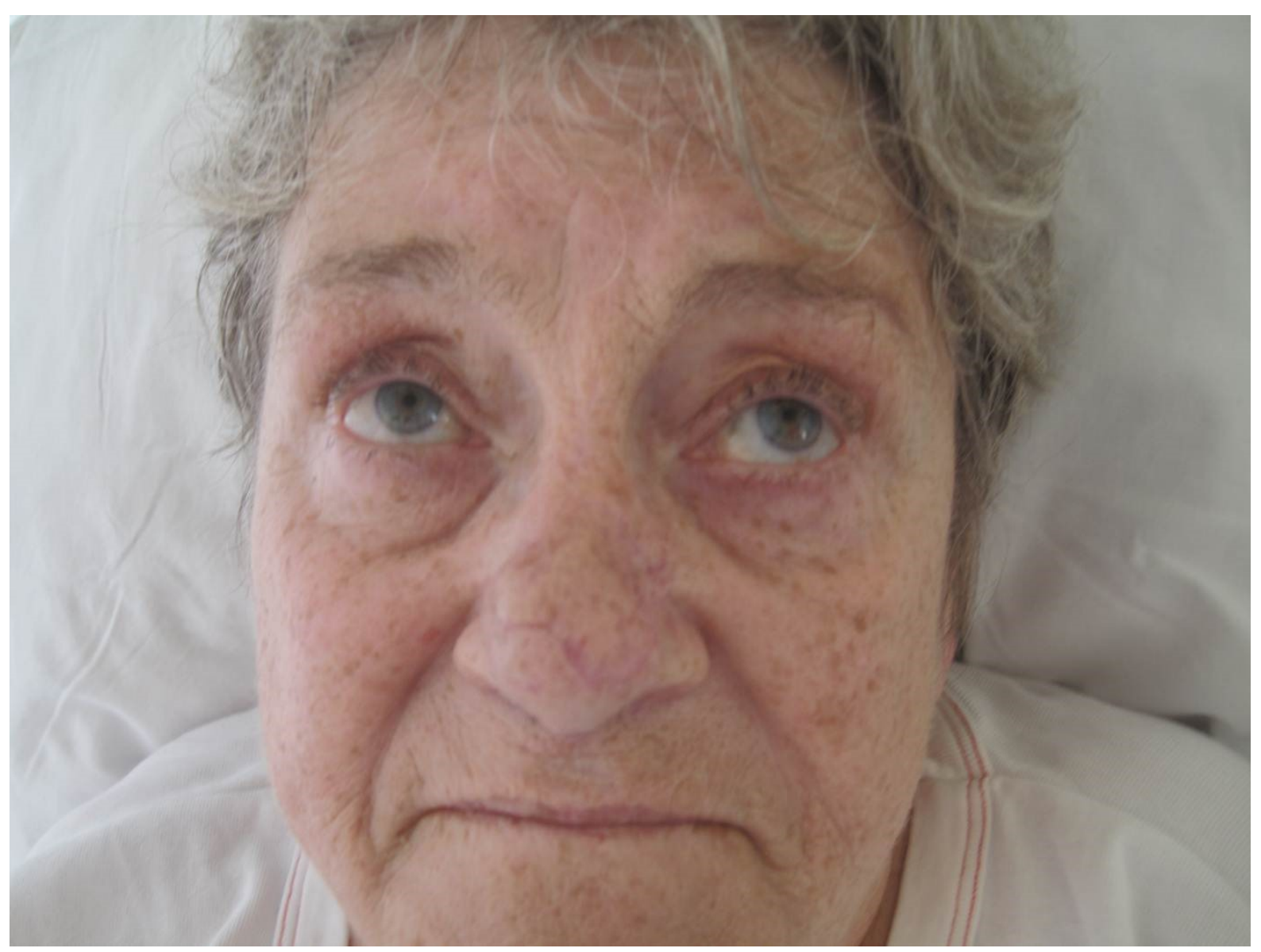

Fig. (1). Spontaneous up gaze in a 62-year-old woman with lithium intoxication. Attempts to look straight ahead elicited downbeat nystagmus.

Lithium intoxication was suspected. Repeated testing of serum lithium revealed an increase to $1.0 \mathrm{mmol} / \mathrm{L}$, and lithium carbonate was discontinued. Within one week serum lithium level decreased to $0.2 \mathrm{mmol} / \mathrm{L}$ and symptoms and signs improved significantly. Serum lamotrigine and valproate levels were only analysed one week after lithium discontinuation when clinical signs and symptoms had improved significantly. At this point lamotrigine and valproate levels were slightly over therapeutic range, serum lamotrigine $66 \mu \mathrm{mol} / \mathrm{L}(4-50 \mu \mathrm{mol} / \mathrm{L})$ and serum valproate 714 $\mu \mathrm{mol} / \mathrm{L}(300-700 \mu \mathrm{mol} / \mathrm{L})$. Due to the marked clinical improvement after lithium discontinuation, the slightly elevated levels of valproate and lamotrigine were not considered causative, and therefore both drugs were continued. Seven weeks after initial presentation at the Neurological Department, vertical and horizontal eye movements had normalized apart from a residual low-amplitude DBN and oscillopsia on down gaze to the right and left. Best corrected visual acuity was 20/16 in each eye. Tremor and cognitive functions had normalized though some degree of retrograde amnesia persisted.

\section{D, 6\&8 66, 21}

We strongly suspect the clinical findings to be caused by lithium carbonate intoxication. Alternative causes of DBN i.e. structural lesions of the craniocervical junction or cerebellum, encephalitis or hypomagnesemia were ruled out, and symptoms improved significantly as lithium carbonate was discontinued.

Vitamin B12 deficiency is known to cause eye movement disorders like DBN and internuclear ophthalmoplegia, as well as gait ataxia $[4,5]$. However, in our patient serum B12 level was normal, and B12 deficiency was therefore not considered the cause of DBN. Differential diagnostic considerations in patients with ataxia and affection of the ocular motility includes Wernicke's encephalopathy as well as paraneoplastic neurological syndromes (PNS). Wernicke's encephalopathy is due to nutritional deficiencies especially thiamine deficiency, and vertical nystagmus has been reported in patients with this condition [6]. Our patient had no history of alcohol abuse or malnutrition making this diagnosis less likely. PNS is an extensive group of disorders that may affect any part of the nervous system and in rare 
cases can cause vertical nystagmus [7]. However, we do not consider this diagnosis probable due to the fast clinical restitution after lithium discontinuation, and test for paraneoplastic autoantibodies was negative.

Lamotrigine toxicity is recently reported to be a rare cause of DBN, and lamotrigine's half-life is extended when used with valproate [8]. Our patient was treated uneventfully with both for a long time and DBN presented only as lithium was added. As levels of valproate and lamotrigine were slightly above therapeutic levels, we cannot rule out an additive toxic effect of lamotrigine, though.

In the presented case did symptoms and signs improve as lithium was discontinued, but this is not always the case. Halmagyi et al. reported four patients with lithium-induced DBN with persisting nystagmus despite lithium discontinuation or reduction [3].

The pathophysiology of lithium-induced DBN is not well understood. Corbett et al. reported a case of lithiuminduced DBN and horizontal gaze palsy very similar to ours, though fatal. Postmortem examination disclosed cell loss in the nuclei prepositus hypoglossi and both medial vestibular nuclei in the lower brainstem [2]. These nuclei are supposed to be a neural integrator of conjungated horizontal eye movements, and are assumed to interconnect with brain structures responsible for vertical eye movements [9]. Experimental damage in the region of the nuclei prepositus hypoglossi and medial vestibular nuclei has produced similar eye motility disorders in rhesus monkies, and the authors therefore suggests that lithium-induced DBN is due to focal neuronal damage to these brainstem structures [2].

\section{C2 1 \&/ 8 6, 21}

DBN with horizontal gaze palsy is a rare condition, and lithium side effects should be considered in lithium-treated patients presenting with DBN, especially if no other metabolic or structural lesion of the brain is identified.

\section{C2 1 ) / , \&7 2 ) \,1 7( 5 ( 67}

The authors confirm that this article content has no conflict of interest.

\section{ACKNOWLEDGEMENT}

Declared none.

\section{References}

[1] Bourgeois JA. Ocular side effects of lithium-a review. J Am Optom Assoc 1991; 62(7): 548-51. [PMID: 1813560]

[2] Corbett JJ, Jacobson DM, Thompson HS, Hart MN, Albert DW. Downbeating nystagmus and other ocular motor defects caused by lithium toxicity. Neurology 1989; 39(4): 481-7. [http://dx.doi.org/10.1212/WNL.39.4.481] [PMID: 2648186]

[3] Halmagyi GM, Lessell I, Curthoys IS, Lessell S, Hoyt WF. Lithium-induced downbeat nystagmus. Am J Ophthalmol 1989; 107(6): 664-70. [http://dx.doi.org/10.1016/0002-9394(89)90265-1] [PMID: 2499196]

[4] Akdal G, Yener GG, Ada E, Halmagyi GM. Eye movement disorders in vitamin B12 deficiency: two new cases and a review of the literature. Eur J Neurol 2007; 14(10): 1170-2. [http://dx.doi.org/10.1111/j.1468-1331.2007.01824.x] [PMID: 17880572]

[5] Mayfrank L, Thoden U. Downbeat nystagmus indicates cerebellar or brain-stem lesions in vitamin B12 deficiency. J Neurol 1986; 233(3): $145-8$.

[http://dx.doi.org/10.1007/BF00314420] [PMID: 3487624]

[6] Suzuki Y, Matsuda T, Washio N, Ohtsuka K. Transition from upbeat to downbeat nystagmus observed in a patient with Wernicke's encephalopathy. Jpn J Ophthalmol 2005; 49(3): 220-2. [http://dx.doi.org/10.1007/s10384-004-0182-8] [PMID: 15944827]

[7] Barata PC, Morgado J, Sousa AP, et al. Breast cancer presents with a paraneoplastic neurologic syndrome. Case Rep Oncol 2012; 5(3): 616-21.

[http://dx.doi.org/10.1159/000345692] [PMID: 23275775]

[8] Alkawi A, Kattah JC, Wyman K. Downbeat nystagmus as a result of lamotrigine toxicity. Epilepsy Res 2005; 63(2-3): 85-8. [http://dx.doi.org/10.1016/j.eplepsyres.2004.11.004] [PMID: 15716057]

[9] Leight RJ, Zee DS. The neurology of eye movements. $4^{\text {th }}$ ed. New York: Oxford University Press 2006.

(C) Jørgensen et al.; Licensee Bentham Open.

This is an open access article licensed under the terms of the Creative Commons Attribution-Non-Commercial 4.0 International Public License (CC BY-NC 4.0) (https://creativecommons.org/licenses/by-nc/4.0/legalcode), which permits unrestricted, non-commercial use, distribution and reproduction in any medium, provided the work is properly cited. 